\title{
A malacofauna bentônica das represas do médio rio Tietê (São Paulo, Brasil) e uma avaliação ecológica das espécies exóticas invasoras, Melanoides tuberculata (Müller) e Corbicula fluminea (Müller)
}

\author{
Ana L Suriani; Roberta S. França \& Odete Rocha \\ Programa de Pós Graduação em Ecologia e Recursos Naturais, Universidade Federal de São Carlos. Rodovia Washington Luís \\ km 235, 13565-905 São Carlos, São Paulo, Brasil. \\ E-mail: analuciabio@bol.com.br, betabio00@bol.com.br, doro@power.ufscar.br
}

\begin{abstract}
Benthic malacofauna of the reservoirs of the Middle River Tietê (São Paulo, Brazil) and an ecological evaluation of the invading exotic species, Melanoides tuberculata (Müller) and Corbicula fluminea (Müller). This study analyze the composition of species, the density and the spatial and temporal distribution of benthic malacofauna in three reservoirs of the Middle Tietê River. The samplings were carried out in two climatic periods, the rainy season in November 2002 and the dry season in August 2003, showing three portions in each reservoir (upper, middle and lower) and following a sweeping with six sampling points in each transect. Based on the limnological data the reservoirs of the Middle Tietê River were eutrophied with high concentrations of nutrients (total and dissolved). Eight species of mollusks were registered, six natives and two exotics. Of these, the dominant species was the exotic and invading mollusk Melanoides tuberculata (Müller, 1774), found in all reservoirs. Another exotic specie Corbicula fluminea (Müller, 1774), was current in all the reservoirs in both periods of sampling (except in the Barra Bonita reservoir). In the Barra Bonita reservoir only the two exotic species occurred, while in the Bariri and Ibitinga the native species Aylacostoma tenuilabris (Bernardi, 1856), Biomphalaria glabrata (Say, 1818), Biomphalaria intermedia (Paraense \& Deslandes, 1962), Diplodon expansus (Küster, 1853), Physa cubensis (Pfeiffer, 1839) and Pomacea canaliculata (Lamarck, 1822) occurred in at least one of the sampled periods. The generalized occupation of $M$. tuberculata and $C$. fluminea and the high densities of these species in the studied reservoirs reveal the invading potential of same and the probable competition with the native species.
\end{abstract}

KEY WORDS. Diversity; ecology of reservoirs; invading mollusks.

RESUMO. Este trabalho analisa a composição de espécies, a densidade e a distribuição espacial e temporal da malacofauna bentônica em três represas do médio rio Tietê. As coletas foram realizadas em dois períodos climáticos, o chuvoso em novembro de 2002 e o seco em agosto de 2003, amostrando-se três porções em cada represa (superior, mediana e barragem) e seguindo uma varredura com seis pontos amostrais em cada transecto. Os dados limnológicos obtidos evidenciaram que as represas do médio rio Tietê encontram-se eutrofizadas com elevadas concentrações de nutrientes (totais e dissolvidos). Foram registradas oito espécies de moluscos sendo seis nativas e duas exóticas. Destas, a espécie dominante foi o molusco exótico e invasor Melanoides tuberculata (Müller, 1774), presente em todas as represas. A outra espécie exótica Corbicula fluminea (Müller, 1774), também esteve presente em todas as represas e em ambos os períodos de coleta (exceto na represa de Barra Bonita). Na represa de Barra Bonita só ocorreram as duas espécies exóticas, enquanto nas represas de Bariri e lbitinga as espécies nativas Aylacostoma tenuilabris (Bernardi, 1856), Biomphalaria glabrata (Say, 1818), Biomphalaria intermedia (Paraense \& Deslandes, 1962), Diplodon expansus (Küster, 1853), Physa cubensis (Pfeiffer, 1839) e Pomacea canaliculata (Lamarck, 1822) ocorreram em pelo menos um dos períodos amostrados. A ocupação generalizada de $M$. tuberculata e $C$. fluminea e as elevadas densidades destas espécies nas represas estudadas revelam $\mathrm{O}$ alto potencial invasor das mesmas e a provável competição com as espécies nativas.

PALAVRAS-CHAVE. Diversidade; ecologia de reservatórios; moluscos invasores.

As represas são ecossistemas artificiais construídos pelo homem visando a acumulação de água para múltiplos usos, entre eles: a produção de energia elétrica, produção de biomassa, transporte, irrigação, recreação, abastecimento doméstico e industrial (TundısI 1988, TundısI et al. 1998).

Em contraposição ao rio, a condição de represa provoca 
alterações no ecossistema aquático, causando modificações na composição química do sedimento, na água, na circulação e na organização das comunidades biológicas, além de influenciar o rio e suas comunidades bióticas a jusante (ARMENGoL et al. 1999).

Dentre as comunidades em represas, a bentônica é de grande relevância devido ao seu papel estrutural e funcional, participando tanto na reciclagem de materiais como no fluxo de energia (KAJAK 1988, Covich et al. 1999). Os moluscos são freqüentemente encontrados entre os grupos formadores desta comunidade, embora sua densi dade seja bastante variável (PAYNE 1986). A malacofauna de água doce no estado de São Paulo está representada por cerca de 35 espécies de Gastropoda (SIMONE 1999) e 44 espécies de Bivalvia (AvelAR 1999), sendo que algumas podem ocorrer em elevada densidade ou biomassa (HENRY \& SimÃo 1984). A composição de espécies e a densidade de moluscos dependem fundamentalmente da combinação de diferentes fatores bióticos e abióticos, particulares a cada ambiente, sendo que algumas associações podem ser utilizadas como indicadoras da qualidade da água e da integridade dos habitats. Espécies indicadoras podem ser uma ferramenta bastante útil, considerando-se as rápidas al terações que vem ocorrendo nas águas doces de todo o mundo, especial mente devido à poluição orgânica e química (STRASKRABA \& TunDISI 1999) e à introdução de espécies invasoras (Espíndola et al. 2003).

Segundo DARRIGAN (1997), são consideradas espécies invasoras, aquelas que, além de serem exóticas, caracterizam-se pela rápida maturação sexual, grande capacidade reprodutiva e um considerável poder adaptativo aos ambientes que colonizam, sejam naturais, artificiais, duciaquícolas ou salobros.

Os moluscos invasores representam uma séria ameaça às espécies nativas, em decorrência da sua supremacia na competição pelo uso dos habitats e recursos tróficos, e em virtude das alterações que provocam nas comunidades bentônicas, afetando negativamente todo o ecossistema invadido (VITOUSEK 1990). Entre as espécies exóticas registradas na América do Sul destacam-se Melanoides tuberculata (Müller, 1774) (Thiaridae) e Corbicula fluminea (Müller, 1774) (Corbiculidae).

Melanoides tuberculata é um gastropode nativo no leste e norte da África, no sudeste da Ásia, na China e nas ilhas do Indo-Pacífico, com uma ampla distribuição nestas áreas (PoINTER et al. 1993). No Brasil, esta espécie foi registrada pela primeira vez na cidade de Santos (São Paulo) em 1967 e deste então, já foi registrada em Brasília (Distrito Federal), Rio de Janeiro (Rio de Janeiro), Minas Gerais (Minas Gerais), Goiás (Goiás) e Espírito Santo (Espírito Santo) (VAZ et al. 1986). A sua introdução no país está provavelmente relacionada ao comércio de plantas e peixes ornamentais (Fernandez et al. 2003).

Corbicula fluminea é um bivalve, conhecido como "Asia clam" e originário da China, que foi introduzido na América do Norte como alimento, pelos chineses, ao redor de 1920. É hermafrodita, atinge um comprimento máximo de $35 \mathrm{~mm}$ e utiliza diferentes tipos de substratos. Segundo STRAYER (1999) ocor- re tanto em lagos como rios e riachos. Em represas, pode ficar aprisionada dentro de trocadores de calor das usinas hidrelétricas, ocasionando graves problemas. Como a água para abastecimento é captada de rios, riachos e represas, as larvas são introduzidas nos tubos de condensadores, canos de água e sistemas de combate a incêndios, entupindo-os após o crescimento dos moluscos, resultando em graves problemas econômicos (HaKenKAmp \& MARGARet 1999). Na América do Sul, a introdução desta espécie em águas do rio da Prata ocorreu nas décadas de 1960 e 1970 (ITUARTE 1981). No Brasil, foi registrada pela primeira vez no Rio Grande do Sul, na bacia do rio Jacuí e do Guaíba, no final da década de 1960 (Veitenheimer-Mendes 1981).

Este trabalho teve como objetivo analisar a composição de espécies, a densidade e a distribuição espacial e temporal da malacofauna bentônica em três represas do médio rio Tietê (Barra Bonita, Bariri e Ibitinga), avaliando o grau de invasão e o possível impacto das espécies exóticas sobre as espécies nativas.

\section{MATERIAL E MÉTODOS}

\section{Área de estudo}

As coletas foram realizadas nas represas de Barra Bonita, Bariri e Ibitinga, no médio rio Tietê, São Paulo, Brasil (Fig. 1). Estas represas foram construídas na segunda metade do século passado, com a finalidade de geração de energia hidroelétrica.

A Bacia do médio rio Tietê abrange uma área de drenagem de aproximadamente $30.800 \mathrm{~km}^{2}$, com extensão total de 625 km e engloba 80 municípios. É uma área de intensa atividade industrial, com forte pressão antrópica (CETESB 2001).

A tabela I apresenta as principais características morfomé tricas e funcionais das represas estudadas.

As coletas foram realizadas nos meses de novembro de 2002 e agosto de 2003, com precipitação mensal média de $204,5 \mathrm{~mm}$ e $21,4 \mathrm{~mm}$, respectivamente. Em cada represa determinaram-se três transectos (barragem, meio e superior), realizando-se uma amostragem em seis pontos de coleta em cada transecto. Estes, por sua vez, foram georeferenciados e distribuídos de acordo com o gradiente de profundidade escal onado em intervalos de 2 a $4 \mathrm{~m}$.

\section{Variáveis abióticas}

As medidas de $\mathrm{pH}$, condutividade elétrica, oxigênio dissolvido e temperatura da água foram realizadas in situ na interface sedimento-água utilizando-se um multisensor da marca Horiba, modelo U-10.

As amostras de água para as análises das concentrações de nutrientes (nitrogênio e fósforo total) e as formas dissolvidas (nitrito, nitrato e amônia) foram coletadas com uma garrafa van Dorn, vertical, de 5 litros, próximo ao fundo, nos diferentes pontos de cada transecto. As amostras foram acondicionadas em frascos de polietileno e congeladas até a análise. No laboratório, partes das amostras foram filtradas em membranas de microfibra de vidro da marca GF/F Whatman, com $47 \mathrm{~mm}$ de diâmetro e 0,7 $\mu \mathrm{m}$ de abertura de poro, a fim de 


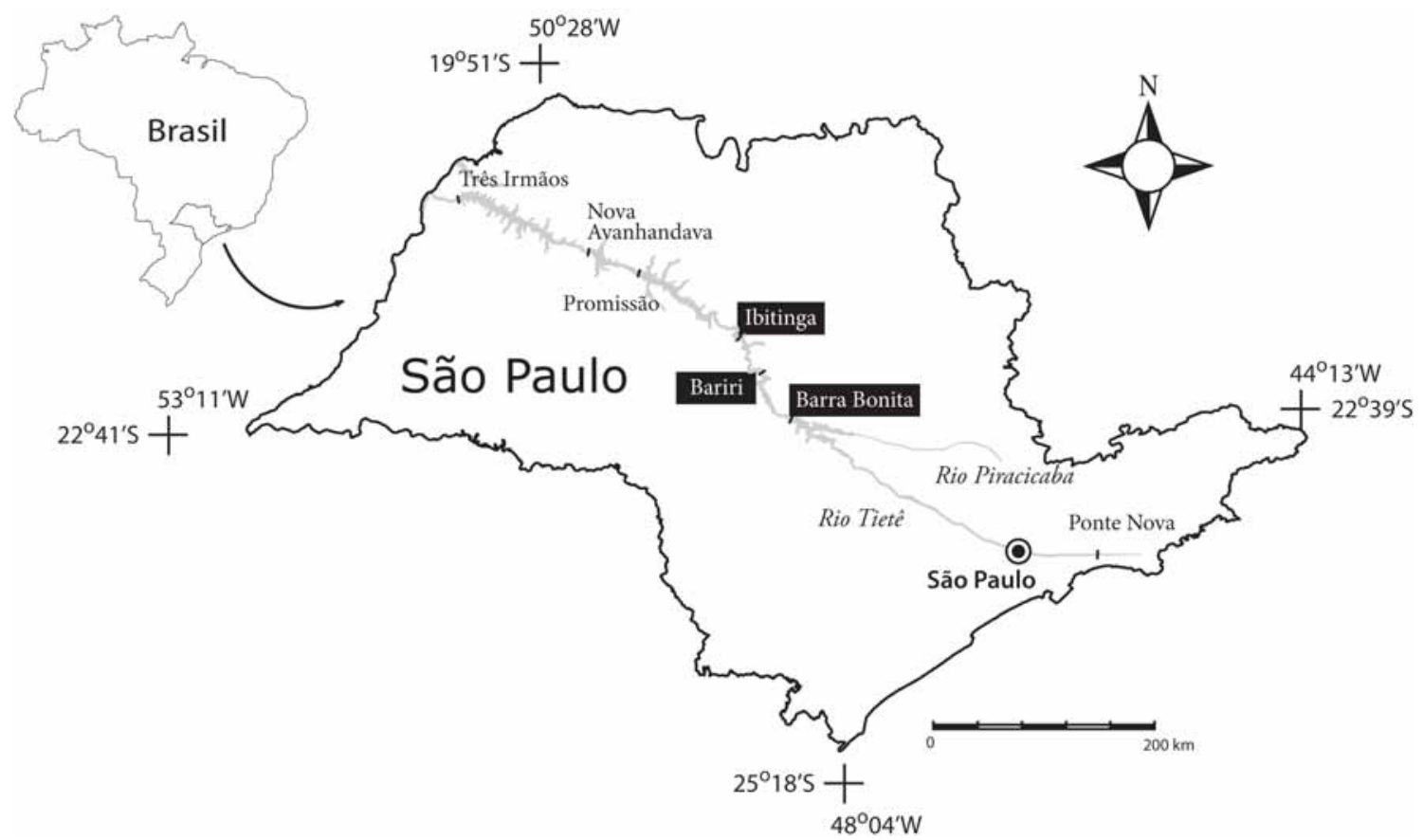

Figura 1. Localização do Rio Tietê no Estado de São Paulo, Brasil, evidenciando as represas do médio rio Tietê: Barra Bonita, Bariri e lbitinga. Modificado de Rocha et al. (2006).

Tabela I. Valores médios do tempo de residência da água, área de inundação, volume total, profundidade média e ano de enchimento das represas do médio rio Tietê/Paraná (CESP 1998).

\begin{tabular}{lccccc}
\hline Represas & Tempo de residência (dias) & Área de inundação $\left(\mathrm{km}^{2}\right)$ & Volume total $\left(\mathrm{m}^{3} \times 10^{6}\right)$ & Profundidade $(\mathrm{m})$ & Ano de enchimento \\
\hline Barra Bonita & 90,3 & 310 & 3135,0 & 10,1 & 1964 \\
Bariri & 14,2 & 63 & 542,5 & 8,6 & 1969 \\
lbitinga & 21,6 & 56 & 981,0 & 8,6 & 1969 \\
\hline
\end{tabular}

reter o material particulado. As concentrações dos principais nutrientes presentes na água foram determinadas por meio de espectrofotometria segundo as metodologias descritas por Golterman et al. (1978) e MAcKereth et al. (1978).

A composição granulométrica e o teor de matéria orgânica dos sedimentos das represas foram determinados em todas as profundidades de cada transecto a partir das amostras coletadas com draga do tipo van Veen, de acordo com a metodologia descrita por Suguio (1973).

\section{Variáveis bióticas}

Em cada ponto, as amostras de sedimento foram coletadas em duplicata com uma draga do tipo van Veen de $337 \mathrm{~cm}^{2}$ de área amostral. Posteriormente, foram lavadas em peneira com $0,21 \mathrm{~mm}$ de abertura de malha e o material retido foi preservado em solução de formol $8 \%$ no próprio local de coleta. No laboratório, os moluscos de conchas íntegras foram triados em uma bandeja trans-iluminada e preservados em álcool a 70\%. Estes organismos foram anal isados sob microscópio estereoscó- pico, com aumento de até 40 vezes.

Os organismos foram identificados até o menor nível taxonômico possível (gênero e espécie), utilizando-se a chave de identificação proposta por THOMPSON (2004) e com o auxílio dos especialistas Dr. Wagner E.P. Avelar, Faculdade de Filosofia, Ciências e Letras de Ribeirão Preto, Universidade de São Paulo e pelo Dr. Luiz Ricardo Lopez de Simone, Museu de Zoologia, Universidade de São Paulo.

Os exemplares de moluscos foram depositados na coleção do Departamento de Ecologia e Biologia Evolutiva, Universidade Federal de São Carlos.

A densidade dos organismos foi calculada a partir da contagem total dos organismos nas amostras, e expressa em relação à área de $1 \mathrm{~m}^{2}$, de acordo com a seguinte fórmula: $\mathrm{N}=(\mathrm{X} / \mathrm{A} . \mathrm{S}) \times 10.000$; onde: $\mathrm{N}$ é o número de indivíduos por metro quadrado, $X$ é o número de organismos contados na amostra, A é a área do amostrador $\left(\mathrm{cm}^{2}\right)$ e S é o número de amostras coletadas em cada ponto amostrado (WELCH 1948). 


\section{Análise estatística}

Realizou-se uma análise de regressão múltipla passo a passo - Stepwise multiple regression (programa NCSSPC) para verificar as possíveis correlações entre as variações na abundância das espécies e as variáveis abióticas.

Por meio de análise de variância multivariada - MANOVA (programa SYSTAT), realizada sobre as matrizes de dados abióticos (períodos chuvoso e seco), testou-se o efeito da sazonalidade, com nível de corte de probabilidade de $5 \%$. O passo seguinte foi preparar duas novas matrizes de dados abióticos e bióticos para a aplicação da anál ise de correspon dência canônica - CCA (programa MVSP 3.1), considerando-se os períodos de coleta.

\section{RESULTADOS E DISCUSSÃO}

\section{Variáveis abióticas}

Os resultados relativos às variáveis abióticas determinadas in situ são apresentados na tabela II. Em geral, o pH de todas as represas variou de ligeiramente ácido a básico, em ambos os períodos de coleta, embora na represa de Bariri tenha sido registrado o valor mínimo de 5,5 em agosto de 2003, indicando uma condição ligeiramente ácida. Ambientes eutróficos como as represas do médio rio Tietê, geralmente tem altos valores de $\mathrm{pH}$ durante o dia devido à intensa fotossíntese (M ARGALEF 1983). Este fenômeno pode ser observado pelos val ores básicos de $\mathrm{pH}$ registrados no presente estudo para a coluna de água nas três represas analisadas, nos dois períodos de coletas.

Os valores médios de condutividade variaram entre $159,06 \mu \mathrm{Scm}^{-1}$ e $317,73 \mu \mathrm{Scm}^{-1}$. Os valores registrados em novembro de 2002 (período chuvoso) foram mais elevados do que aqueles obtidos em agosto de 2003 (período seco), em todas as represas, resultantes, provavelmente, do grande aporte de materiais pelos rios afluentes, Tietê e Piracicaba, ambos bastante eutróficos, em virtude da carga de efluentes industriais e domésticos. O valor máximo de $373 \mu \mathrm{Scm}^{-1}$ foi registrado na represa de Barra Bonita, no período chuvoso. Fracácıo et al. (2003) registraram um valor médio de condutividade da água de $136 \mu \mathrm{Scm}^{-1}$ para as três represas, inferior ao encontrado no presente estudo.

Os valores médios da concentração de oxigênio dissolvido nos períodos de novembro de 2002 e agosto de 2003 foram respectivamente: $5,62 \mathrm{mgl}^{-1}$ e 7,73 $\mathrm{mgl}^{-1}$, em Barra Bonita; $8,54 \mathrm{mgl}^{-1}$ e 7,39 $\mathrm{mgl}^{-1}$, em Bariri e 10,12 $\mathrm{mgl}^{-1}$ e 8,79 $\mathrm{mgl}^{-1}$, em Ibitinga. A concentração do oxigênio dissolvido tende a diminuir no período de chuvas devido ao aumento da concentração da matéria orgânica carreada dos sistemas terrestres circundantes pelo escoamento superficial, oriundo das intensas precipitações pluviométricas ou por meio de tributários (PAYNe 1986). Este fato foi observado na represa de Barra Bonita, quando comparadas às concentrações de oxigênio da água nos períodos seco e chuvoso. A coluna d'água das represas foi bastante oxigenada na zona eufótica em decorrência das el evadas taxas fotossintéticas, ocorrendo, contudo, nas maiores profundidades, camadas com baixa concentração de oxigênio ou mesmo anoxia. As baixas concentrações de oxigênio observadas próximo ao sedimento podem ser limitantes para alguns elementos da comunidade bentônica, entre eles os moluscos. Segundo MCMAHON (1983) C. fluminea, em águas lênticas, vive preferencialmente em águas superficiais e bem oxigenadas.

Para a temperatura da água, os val ores médios registrados nas represas durante os períodos de amostragem evidenciaram uma variação sazonal, sendo o maior valor 28,9 드. encontrado em novembro de 2002 (período chuvoso), na represa de Barra Bonita e o menor valor $18,7 \circ \mathrm{C}$ registrado na represa de Bariri no mês de agosto de 2003 (período seco).

Tabela II. Valores máximos (Mx), médios (Me), mínimos $(\mathrm{Mn})$ e desvio padrão para as variáveis físicas e químicas da água nas represas de Barra Bonita, Bariri e lbitinga em novembro de 2002 e agosto de 2003.

\begin{tabular}{|c|c|c|c|c|c|c|c|c|c|c|c|c|c|}
\hline \multirow[t]{2}{*}{ Represas } & \multirow[t]{2}{*}{ Meses } & \multicolumn{3}{|c|}{$\mathrm{pH}$} & \multicolumn{3}{|c|}{$\begin{array}{c}\text { Condutividade } \\
\left(\mu \mathrm{S} . \mathrm{cm}^{-1}\right)\end{array}$} & \multicolumn{3}{|c|}{$\begin{array}{l}\text { Oxigênio Dissolvido } \\
\left(\mathrm{mg} . \mathrm{I}^{-1}\right)\end{array}$} & \multicolumn{3}{|c|}{$\begin{array}{c}\text { Temperatura } \\
(\stackrel{\mathrm{C}}{ }) \\
\end{array}$} \\
\hline & & $M x$ & $\mathrm{Me}$ & $\mathrm{Mn}$ & $\mathrm{Ma}$ & $\mathrm{Me}$ & $\mathrm{Mn}$ & $M x$ & $\mathrm{Me}$ & $\mathrm{Mn}$ & $M x$ & $\mathrm{Me}$ & $\mathrm{Mn}$ \\
\hline \multirow[t]{4}{*}{ Barra Bonita } & Nov. 2002 & 10,26 & 8,88 & 7,52 & 373,00 & 317,83 & 275 & 14,05 & 5,62 & 0 & 28,90 & 25,44 & 23,4 \\
\hline & Desvio padrão & 0,67 & & & 26,00 & & & 4,38 & & & 1,52 & & \\
\hline & Ago. 2003 & 8,64 & 7,44 & 6,59 & 234,00 & 219,50 & 210 & 10,52 & 7,73 & 6,48 & 20,50 & 19,08 & 18,8 \\
\hline & Desvio padrão & 0,58 & & & 9,32 & & & 0,72 & & & 0,41 & & \\
\hline \multirow[t]{4}{*}{ Bariri } & Nov. 2002 & 10,54 & 7,99 & 6,34 & 354,00 & 306,76 & 263 & 13,58 & 8,54 & 1,48 & 28,60 & 25,61 & 23,7 \\
\hline & Desvio padrão & 1,47 & & & 39,16 & & & 3,25 & & & 1,31 & & \\
\hline & Ago. 2003 & 9,28 & 7,66 & 5,49 & 225,00 & 195,84 & 120 & 13,47 & 7,39 & 4,83 & 21,40 & 19,57 & 18,7 \\
\hline & Desvio padrão & 0,76 & & & 10,33 & & & 2,07 & & & 0,72 & & \\
\hline \multirow[t]{4}{*}{ Ibitinga } & Nov. 2002 & 11,18 & 8,75 & 6,31 & 515,00 & 255,26 & 218 & 19,60 & 10,12 & 0,98 & 28,10 & 25,93 & 24,4 \\
\hline & Desvio padrão & 1,36 & & & 40,34 & & & 4,20 & & & 1,07 & & \\
\hline & Ago. 2003 & 8,96 & 7,90 & 6,32 & 185,00 & 159,06 & 146 & 13,61 & 8,79 & 4,43 & 23,30 & 20,21 & 19,4 \\
\hline & Desvio padrão & 0,70 & & & 13,78 & & & 1,72 & & & 0,90 & & \\
\hline
\end{tabular}

Revista Brasileira de Zoologia 24 (1): 21-32, março 2007 
Os valores médios das concentrações dos nutrientes, dissolvidos e totais, registrados na coluna de água das represas de Barra Bonita, Bariri el bitinga, em novembro de 2002 e em agosto de 2003, respectivamente, são apresentados na tabela III.

As maiores concentrações dos compostos nitrogenados inorgânicos foram registrados na represa de Barra Bonita, embora a maior concentração média de nitrogênio orgânico total $\left(6,03 \mathrm{mgl}^{-1}\right)$ tenha sido registrada na represa de Ibitinga, em novembro de 2002, um valor muito superior àqueles encontrados nas outras represas. No período chuvoso, a forma mais abundante de nitrogênio foi o nitrato, com o valor máximo de $3676,\left.48 \mu^{-1}\right|^{-1}$ registrado na represa de Barra Bonita, que comparado com o valor máximo de $1400 \mu \mathrm{g.l^{-1 }}$ encontrado por Tundisı (1990) nesta mesma represa evidencia o aumento do grau de trofia dos ambientes estudados.

Os maiores valores médios das concentrações dos compostos fosfatados também foram encontrados na represa de

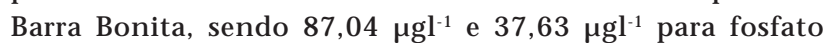
inorgânico, $111,77 \mathrm{mgl}^{-1}$ e $54,00 \mathrm{mgl}^{-1}$ para fosfato dissolvido total e $205,59 \mathrm{\mu gl}^{-1}$ e $111,10 \mathrm{\mu gl}^{-1}$ para fósforo total, em novembro de 2002 e agosto de 2003, respectivamente. Nas represas do médio Tietê, durante o período chuvoso, a forma mais abundante dos compostos fosfatados foi o fosfato dissolvido total, com valores de $111,77 \mu^{g^{-1}}$ na represa de Barra Bonita, 68,05 $\mu \mathrm{gl}^{-1}$ em Bariri e 25,20 $\mathrm{gl}^{-1} \mathrm{em}$ Ibitinga. BARBOSA et al. (1999) registraram valores médios de fósforo total mais elevado nas represas de Barra Bonita $\left(62,6 \mu \mathrm{gl}^{-1}\right)$, Bariri $\left(87 \mu \mathrm{gl}^{-1}\right)$ e Ibitinga $\left(36,9 \mu \mathrm{gl}^{-1}\right)$, o que pode indicar um grande aporte de nutrientes nestas represas, neste período do ano, e a possibilidade delas serem influenciadas por outros sistemas, como os rios Tietê, Piracicaba e Bauru.

Os valores relativos às concentrações médias de matéria orgânica, areia, silte e argila presentes no sedimento, nos períodos de coleta, são apresentados na tabela IV. Observou-se que os sedimentos das represas de Barra Bonita, Bariri e Ibitinga foram predominantemente arenosos. Entretanto, nos sedimentos da região próxima à barragem, na represa de Bariri, ocorreu uma participação maior da fração argila. O sedimento das represas do médio rio Tietê não foi considerado um sedimento orgânico, pois contêm menos de $10 \%$ de matéria orgânica (EsteVes 1998). Nas represas de Barra Bonita e Bariri, a distribuição da fração areia decresceu da porção superior à barragem, devido à maior deposição dessa fração, ocorrendo o inverso com as partículas finas (silte e argila).

\section{Variáveis bióticas}

$\mathrm{Na}$ tabela $\mathrm{V}$ são apresentados os resultados relativos à composição taxonômica, o número total de indivíduos coletados e a abundância relativa das espécies de moluscos, em ambos os períodos, nas três represas, considerando-se os pontos amostrados.

Nas represas de Bariri e Ibitinga as espécies nativas Aylacostoma tenuilabris (Bernardi, 1856) (Thiaridae), Biomphalaria glabrata (Say, 1818) eBiomphalaria intermedia (Paraense \& Deslan-

Tabela III. Valores médios das concentrações dos nutrientes dissolvidos e totais da água das represas do médio Tietê, em novembro de 2002 (período chuvoso) e em agosto de 2003 (período seco).

\begin{tabular}{|c|c|c|c|c|c|c|}
\hline \multirow{2}{*}{ Nutrientes } & \multicolumn{2}{|c|}{ Barra Bonita } & \multicolumn{2}{|c|}{ Bariri } & \multicolumn{2}{|c|}{ Ibitinga } \\
\hline & Nov/2002 & Ago/2003 & Nov/2002 & Ago/2003 & Nov/2002 & Ago/2003 \\
\hline Nitrito $\left(\mu \mathrm{gl}^{-1}\right)$ & 222,61 & 88,42 & 106,20 & 25,60 & 29,76 & 10,68 \\
\hline Nitrato $\left(\mu \mathrm{gl}^{-1}\right)$ & 3678,48 & 1246,09 & 2780,14 & 984,57 & 1650,45 & 821,70 \\
\hline Amônia $\left(\mu \mathrm{gl}^{-1}\right)$ & 163,53 & 92,27 & 96,89 & 63,74 & 31,77 & 45,12 \\
\hline Nitrogênio orgânico total $\left(\mathrm{mgl}^{-1}\right)$ & 1,82 & 0,08 & 1,49 & 0,53 & 6,03 & 0,38 \\
\hline Fosfato inorgânico $\left(\mu \mathrm{gl}^{-1}\right)$ & 87,04 & 37,63 & 48,46 & 10,43 & 10,66 & 3,19 \\
\hline Fosfato dissolvido total $\left(\mu \mathrm{gl}^{-1}\right)$ & 111,77 & 54,00 & 68,05 & 23,96 & 25,20 & 11,50 \\
\hline Fósforo total $\left(\mu \mathrm{gl}^{-1}\right)$ & 205,59 & 111,10 & 162,28 & 70,09 & 148,54 & 84,06 \\
\hline
\end{tabular}

Tabela IV. Contribuição percentual média de matéria orgânica, areia, silte e argila presentes no sedimento das represas de Barra Bonita, Bariri e lbitinga, em novembro de 2002 e agosto de 2003.

\begin{tabular}{|c|c|c|c|c|c|c|c|c|c|c|c|c|c|c|c|c|c|c|}
\hline & \multicolumn{6}{|c|}{ Barra Bonita } & \multicolumn{6}{|c|}{ Bariri } & \multicolumn{6}{|c|}{ Ibitinga } \\
\hline & \multicolumn{3}{|c|}{ Nov/2002 } & \multicolumn{3}{|c|}{ Ago/2003 } & \multicolumn{3}{|c|}{ Nov/2002 } & \multicolumn{3}{|c|}{ Ago/2003 } & \multicolumn{3}{|c|}{ Nov/2002 } & \multicolumn{3}{|c|}{ Ago/2003 } \\
\hline & $S$ & $M$ & $B$ & $\mathrm{~S}$ & $M$ & B & $\mathrm{S}$ & $M$ & $B$ & $\mathrm{~S}$ & $M$ & $B$ & $\mathrm{~S}$ & $M$ & $B$ & $S$ & $M$ & $B$ \\
\hline M. O. (\%) & 2,4 & 3,9 & 3,8 & 2,5 & 1,4 & 3,0 & 1,4 & 6,9 & 7,8 & 1,5 & 6,1 & 6,4 & 3,3 & 5,8 & 6,2 & 3,8 & 5,9 & 4,0 \\
\hline Areia (\%) & 78,8 & 74,9 & 70,0 & 80,5 & 90,0 & 70,6 & 87,1 & 41,5 & 40,8 & 89,2 & 44,2 & 39,9 & 57,7 & 50,3 & 60,3 & 58,5 & 54,9 & 69,6 \\
\hline Silte (\%) & 5,2 & 6,7 & 12,9 & 3,7 & 2,4 & 8,4 & 4,7 & 16,7 & 16,7 & 2,8 & 8,1 & 17,2 & 17,5 & 19,7 & 11,4 & 16,5 & 16,3 & 9,7 \\
\hline Argila (\%) & 15,9 & 18,4 & 17,1 & 15,8 & 7,7 & 21,0 & 8,3 & 41,8 & 42,6 & 8,2 & 47,7 & 42,9 & 24,8 & 30,0 & 28,3 & 25,0 & 28,8 & 20,7 \\
\hline
\end{tabular}


Tabela V. Composição taxonômica, número total de indivíduos e abundância relativa (Ab. rel.) de cada táxon coletado nas represas de Barra Bonita, Bariri e Ibitinga, em novembro de 2002 (chuvoso) e agosto de 2003 (seco).

\begin{tabular}{|c|c|c|c|c|c|c|c|c|c|}
\hline & \multicolumn{3}{|c|}{ Barra Bonita } & \multicolumn{3}{|c|}{ Bariri } & \multicolumn{3}{|c|}{ Ibitinga } \\
\hline & \multicolumn{2}{|c|}{ Número de indivíduos } & \multirow{2}{*}{$\begin{array}{c}\text { Ab. rel. } \\
(\%)\end{array}$} & \multicolumn{2}{|c|}{ Número de indivíduos } & \multirow{2}{*}{$\begin{array}{c}\text { Ab. rel. } \\
(\%)\end{array}$} & \multicolumn{2}{|c|}{ Número de indivíduos } & \multirow{2}{*}{$\begin{array}{c}\text { Ab. rel. } \\
(\%)\end{array}$} \\
\hline & Nov/2002 & Ago/2003 & & Nov/2002 & Ago/2003 & & Nov/2002 & $\mathrm{Ago} / 2003$ & \\
\hline \multicolumn{10}{|l|}{ Gastropoda } \\
\hline M. tuberculata & 77 & 102 & 98,90 & 470 & 770 & 68,13 & 1248 & 2852 & 85,97 \\
\hline A. tenuilabris & 0 & 0 & 0 & 3 & 11 & 0,77 & 3 & 42 & 0,94 \\
\hline B. glabrata + intermedia & 0 & 0 & 0 & 10 & 89 & 5,44 & 98 & 206 & 6,37 \\
\hline P. cubensis & 0 & 0 & 0 & 4 & 3 & 0,38 & 43 & 78 & 2,54 \\
\hline P.canaliculata & 0 & 0 & 0 & 3 & 1 & 0,22 & 0 & 6 & 0,13 \\
\hline \multicolumn{10}{|l|}{ Bivalvia } \\
\hline C. fluminea & 0 & 2 & 1,10 & 248 & 207 & 25,00 & 99 & 94 & 4,05 \\
\hline D. expansus & 0 & 0 & 0 & 1 & 0 & 0,05 & 0 & 0 & 0 \\
\hline
\end{tabular}

des, 1962) (Planorbidae), Physa cubensis (Pfeiffer, 1839) (Physidae) e Pomacea canaliculata (Lamarck, 1822) (Ampullariidae) ocorreram em pelo menos um dos períodos amostrados. Observou-se que a abundância das espécies nativas foi inferior àquela das espécies exóticas, M. tuberculata e $C$. fluminea.

$\mathrm{Na}$ represa de Barra Bonita só foram registradas as duas espécies exóticas $M$. tuberculata e $C$. fluminea, com uma abundância relativa de 98,90 e 1,10\%, respectivamente.

Na represa de Bariri, embora ainda haja a ocorrência das espécies nativas, as espécies exóticas M. tuberculata e C. fluminea foram as mais abundantes. No presente estudo o bivalve Diplodon expansus (Küster, 1853) (Hyriidae) foi encontrado apenas nessa represa, representado por apenas por um indivíduo, coletado em novembro de 2002 (período chuvoso), indicando ser uma espécie rara.

A maior abundância de moluscos ocorreu na represa de Ibitinga, constituídos principalmente por M. tuberculata, com abundância de 2852 indivíduos e densidade máxima de 5503 ind. $\mathrm{m}^{2}$ no período seco. PAMPLIN \& Rocha (2005) em um estudo realizado na represa de Bariri registrou um valor inferior de 4787,50 ind.m² para esta espécie. Segundo Pointier \& Delay (1995), as características biológicas e o tipo de reprodução partenogenética desta espécie faz dela um bom invasor, apresentando grande adaptabilidade a diferentes condições ambientais e elevada capacidade reprodutiva.

No presente estudo a reduzida abundância dos moluscos nativos nas represas do médio rio Tietê, comparada à abundância das espécies exóticas, pode indicar, portanto, um processo de invasão bem sucedida. Na represa da Pampulha, em Belo Horizonte, Minas Gerais, FreITAS et al. (1987) verificaram que neste sistema $M$. tuberculata se tornou dominante entre as espécies de moluscos, logo após a invasão.

Existem evidências de que $M$. tuberculata é um grande competidor de B. glabrata, conforme foi observado nas represas de Bariri e Ibitinga. Em um estudo realizado na ilha de San- ta Lúcia, Pointier \& JouRdAne (2000) verificaram que estemolusco invasor teve um importante papel na redução e manutenção da população de B. glabrata em baixas densidades, sugerindo que poderia até, eventualmente, levar à extinção desta espécie. Em um riacho do campus da Fundação Oswal do Cruz, FERnANDEZ et al. (2001) registraram um declínio de Pomacea lineata (Spix, 1827) (Ampullariidae) em decorrência da competição por $M$. tuberculata. Pela mesma razão Fernandez et al. (2003) também observaram o declínio de $A$. tenuilabris no rio Tocantins.

Melanoides tuberculata é muito prolífico (JACOBSON 1975) e esta é uma das razões pelas quais as mudanças observadas na malacofauna límnica provavelmente decorrem da competição biológica entre as espécies. Contudo, em determinadas circunstâncias, alterações na composição taxonômica da malacofauna são decorrentes da ação combinada de fragmentação dos habitats e do processo de invasão por espécies exóticas (EspíndolA et al. 2003). De acordo com Dudgeon (1989), o sucesso de M. tuberculata como competidor deve-se à reprodução partenogenética, à rápida maturação sexual, viviparidade e à alta taxa de sobrevivência, podendo ter uma forte vantagem competitiva por espaço e por recursos em habitats instáveis (Pointier et al. 1991).

Corbicula fluminea, apesar de não ocorrer em elevadas densidades, esteve presente em todas as represas e em ambos os períodos de coleta (exceto na represa de Barra Bonita), evidenciando uma alta capaci dade de dispersão e invasão. Em Barra Bonita, este molusco foi registrado somente no período seco, na porção superior e nas profundidades 5 e 7m (Fig. 2).

A densidade máxima de $C$. fluminea registrada na represa de Bariri foi de 1499 ind. $m^{-2}$ na porção superior, em novembro de 2002. Para a espécie $M$. tuberculata o maior valor de densidade foi 1870 ind. $\mathrm{m}^{-2}$, na porção superior, na profundidade de 3,5m durante o período chuvoso (Fig. 3). Nesta represa, em novembro de 2002, observou-se uma diminuição da densidade das espécies invasoras da porção superior em direção à barragem. 


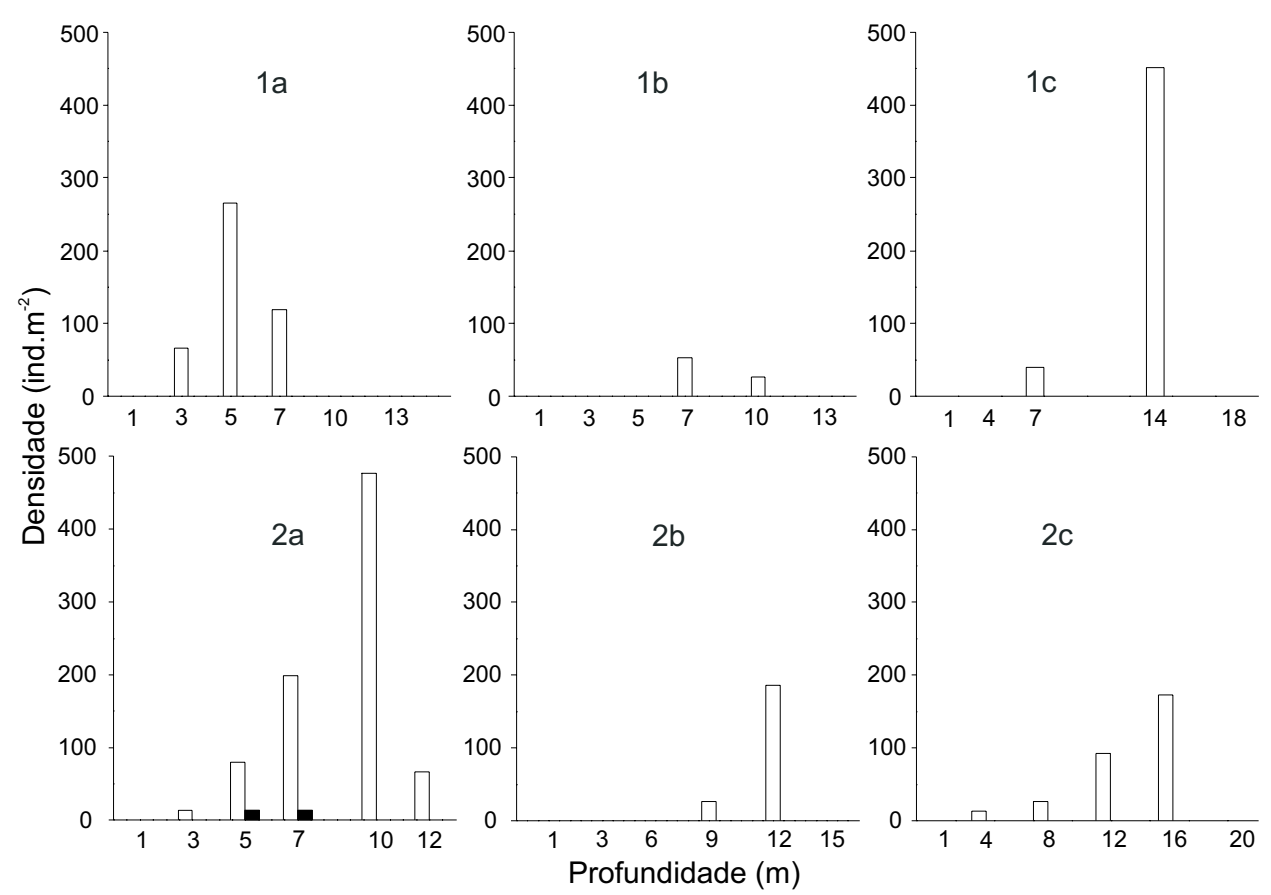

Melanoides tuberculata Corbicula fluminea

Figura 2. Densidade de M. tuberculata e C. fluminea na represa de Barra Bonita nas porções superior (1a), mediana (1b) e barragem (1c), em novembro de 2002, e nas porções superior (2a), mediana (2b) e barragem (2c), em agosto de 2003.

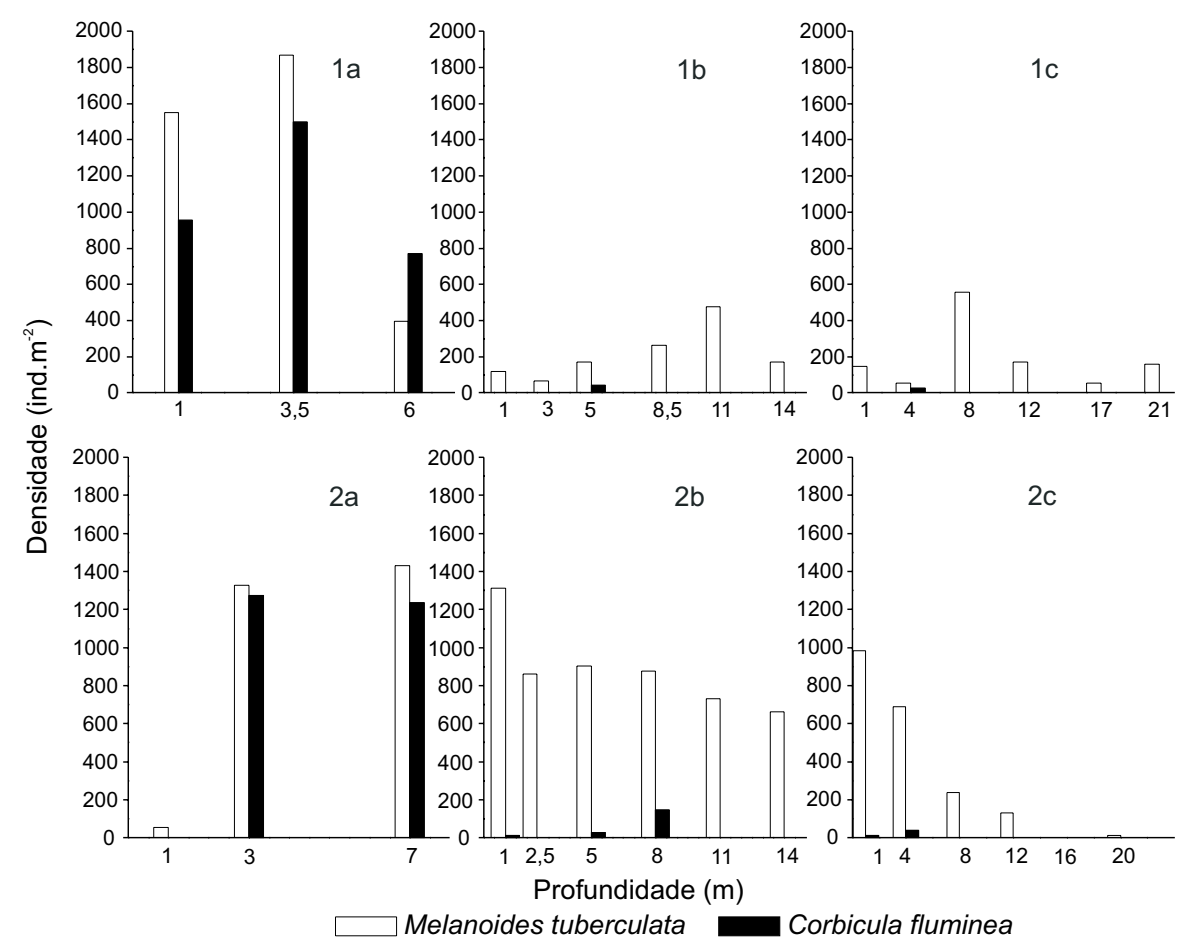

Figura 3. Densidade de M. tuberculata e C. fluminea na represa de Bariri nas porções superior (1a), mediana (1b) e barragem (1c), em novembro de 2002, e nas porções superior (2a), mediana (2b) e barragem (2c), em agosto de 2003. 


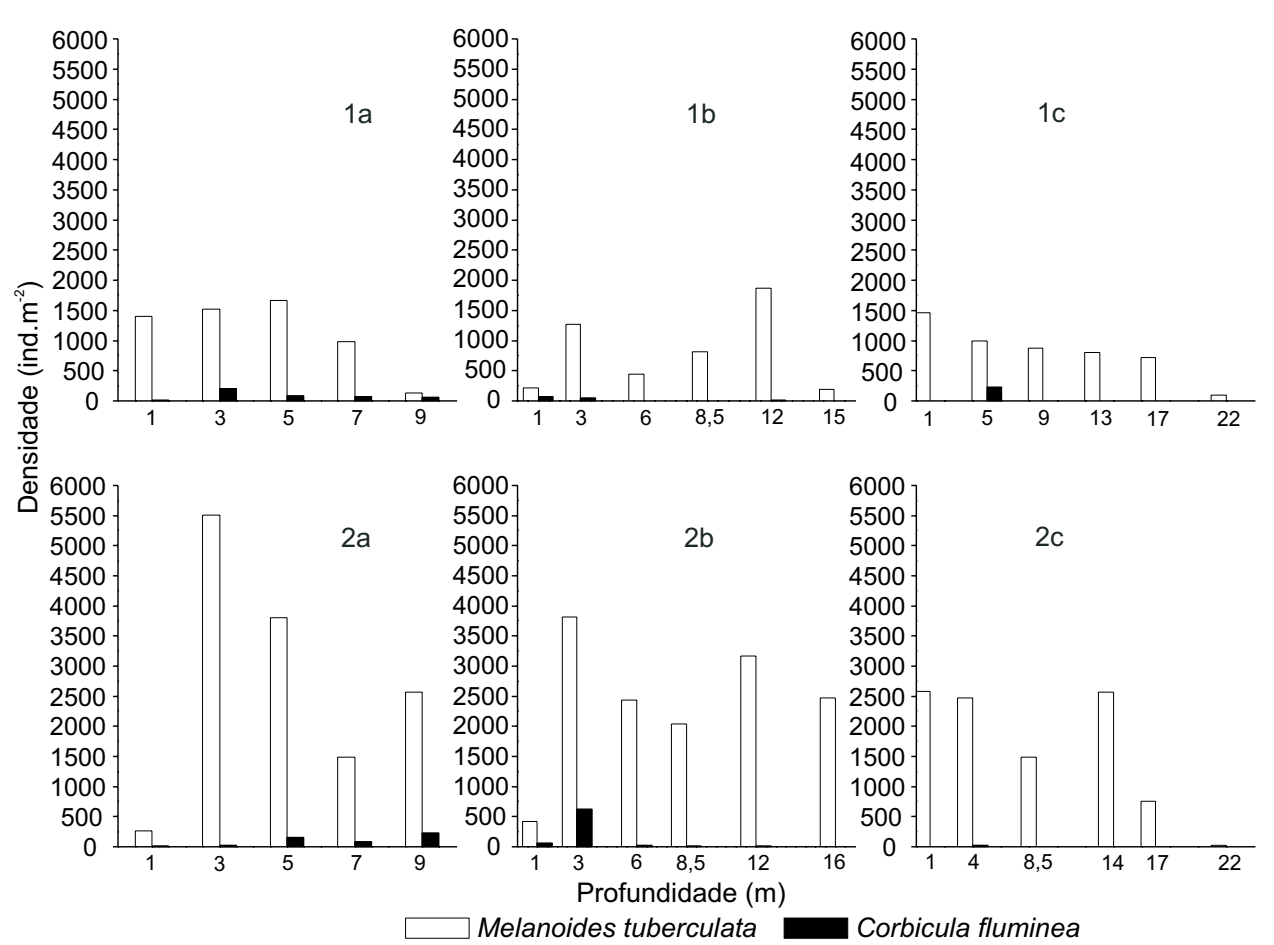

Figura 4. Densidade de M. tuberculata, C. fluminea e P. cubensis na represa de Ibitinga nas porções superior (1a), mediana (1b) e barragem (1c), em novembro de 2002, e nas porç̃̃es superior (2a), mediana (2b) e barragem (2c), em agosto de 2003.
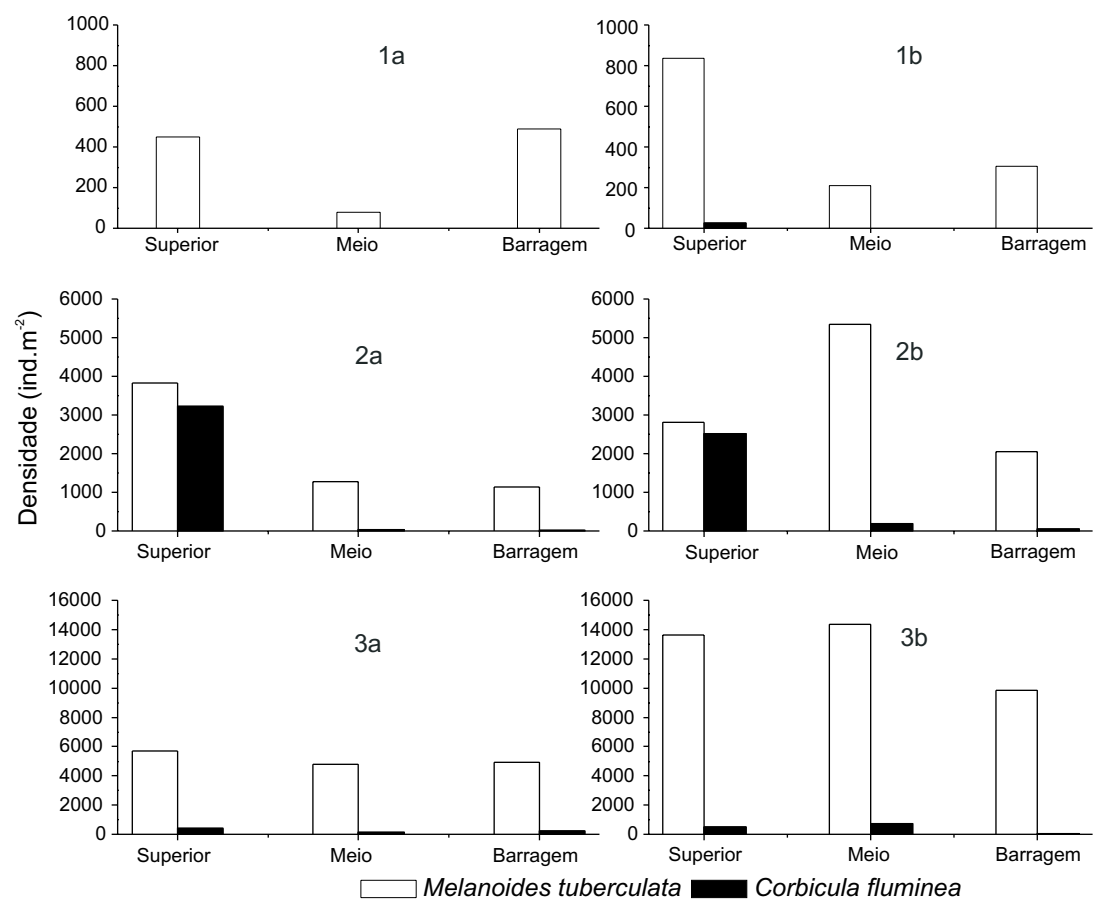

Figura 5. Densidade total de M. tuberculata e C. fluminea nas três porções das represas de Barra Bonita (1), Bariri (2) e lbitinga (3) em novembro de 2002 (a) e em agosto de 2003 (b). 
Na represa de Ibitinga os maiores valores de densidade de M. tuberculata ocorreram em agosto de 2003, com 5503 ind.m 2, na porção superior, na profundidade de 3 m (Fig. 4).

$\mathrm{Na}$ figura 5 pode-se observar que nas três represas de médio Tietê, $M$. tuberculata foi dominante em todas as regiões da represa em ambos os períodos. Quando as três represas foram comparadas (por transectos), o maior valor de densidade de M. tuberculata foi observado na represa de Ibitinga, atingindo o valor máximo de 14337 ind.m², na porção mediana, em agosto de 2003. Já em Bariri, a espécie C. fluminea foi registrada com maiores val ores de densidade na porção superior com 3223 ind. $\mathrm{m}^{-2}$, em novembro de 2002 e com 2507 ind. $\mathrm{m}^{-2}$, em agosto de 2003. Em Barra Bonita foram registrados os menores valores de densidade das espécies exóticas $M$. tuberculata e $C$. fluminea, evidenciando que neste local fatores abióticos ou bióticos podem ser restritivos, mesmo para essas espécies invasoras.

A introdução de espécies não nativas seja acidental ou intencionalmente para o controle biológico de espécies não desejadas, traz prejuízos às comunidades naturais e também ao homem, por interferir no funcionamento dos sistemas. $O$ fato mais preocupante é que, muitas vezes, as espécies são introduzidas sem que haja um estudo detal hado de sua ecologia e desta maneira acabam por afetar, além da espécie-alvo, as outras espécies nativas (Simberloff \& Stiling 1996). Segundo WiLlianson \& FitTeR (1996) para cada dez espécies importadas, introduzidas intencional ou casualmente, uma se estabelece e destas uma em cada dez tem potencial para se transformar em "praga". Infelizmente, a introdução de espécies exóticas vem se tornando uma prática não intencional cada vez mais comum.

A avaliação dos danos causados por uma espécie invasora à biota nativa requer um monitoramento por períodos longos e uma comparação da biota antes e depois da invasão. Em um estudo previamente realizado na represa de Bariri, no médio rio Tietê, PAMPLIN \& Rocha (2005) registraram a ocorrência das espécies exóticas $M$. tuberculata e $C$. fluminea e das espécies nativas A. tenuilabris, Biomphalaria sp. (Planorbidae) eP. cubensis. $M$. tuberculata e $C$. fluminea foram dominantes nessa represa, representando $62,2 \%$ e $15,6 \%$ da abundância total de moluscos, respectivamente.

Os resultados obtidos por meio de análise de regressão múltipla passo a passo não indicaram correlação significativa entre a abundância dos moluscos e as variáveis abióticas medidas nesse trabalho.

A análise multivariada MANOVA revelou que houve variação significativa dos fatores físicos e químicos da água entre os períodos chuvoso e seco, evidenciando a existência de sazonalidade ( $p<0,05)$, expressas principalmente pelas variações na temperatura, concentração de oxigênio dissolvido e de nutrientes.

A análise de correspondência canônica (CCA) para o período chuvoso (Fig. 6) permitiu a explicação de 92,13\% da variância total dos dados.

O eixo 1 explicou 72,64\% da variância dos dados. Nesta análise observou-se que os mais elevados valores de amônio, nitrito, condutividade e a predominância da fração areia, ocorreram na porção superior da represa de Bariri. Nessa porção da represa foi registrada a associação da espécie C. fluminea à fração areia do sedimento. Isto parece refletir uma característica da espécie, pois segundo STRAYER (1999) este bivalve é preferencialmente encontra-se em sedimentos arenosos e bem oxigenados. As espécies A. tenuilabris, B. glabrata, B. intermedia e M. tuberculata pareceram não ter exigência em relação ao tamanho das partículas do sedimento associando-se a todas as classes granulométricas do substrato, durante o período chuvoso. Em Hong Kong, na represa de Plover Cove, Dudgeon (1989) associou o sucesso da ocupação de M. tuberculata em locais com atividade agrícola, em parte à sua preferência por argila e silte.

O eixo 2 explicou 19,495\% da variância dos dados. Podese observar uma maior abundância de P. cubensis na porção superior de Ibitinga enquanto apenas um indivíduo de D. expansus foi coletado na porção inferior, próximo à barragem de Bariri. Esta espécie encontra-se na lista de espécies de invertebrados ameaçados de extinção (MMA 2003). Em razão da projeção positiva das variáveis nitrogênio orgânico total e fósforo total, nesse eixo, verificou-se que essas variáveis podem estar relacionadas à maior disponibilidade de matéria orgânica ou alimento, que possi bilitam a ocorrência de P. cubensis em elevada abundância.

A análise de correspondência canônica realizada com os parâmetros obtidos para o período seco (Fig. 7) permitiu explicar 95,07\% da variância total dos dados.

O eixo 1 explicou 81,79\% da variância, sendo que neste período $C$. fluminea apareceu associado a elevados valores de areia no sedimento e de nitrogênio orgânico total, registrados nas porções superior e próximo à barragem da represa de Bariri.

O eixo 2 explicou 13,28\% da variância. Elevadas concentrações de nitrito, amônio e fosfato inorgânico tiveram relação positiva com este eixo e indicaram uma condição de elevada eutrofização na porção mediana de Bariri. Para as espécies $B$. glabrata, B. intermedia, M. tuberculata, P. canaliculata, A. tenuilabris e $P$. cubensis não houve nenhuma associação particular com valores extremos das variáveis abióticas.

O fato dos moluscos nativos A. tenuilabris, D. expansus, B. glabrata, B. intermedia, P. cubensis e P. canaliculata estarem relacionados com diferentes variáveis ambientais em cada um dos períodos amostrados, demonstra que a partir dos dados obtidos no presente estudo não é possível estabelecer que característica ou variável ambiental esteja diretamente relacionada com essas espécies ou que fator ou combinações de fatores realmente determinam a presença e abundância das mesmas, sugerindo que estudos biológicos mais aprofundados são ainda necessários.

Melanoides tuberculata não se associou a nenhum eixo particular, mostrando ampla tolerância às condições ambientais, tal como se observa para a maioria das espécies invasoras. Estas características indicaram também a magnitude das dificuldades para o manejo e controle da mesma nas represas.

Revista Brasileira de Zoologia 24 (1): 21-32, março 2007 


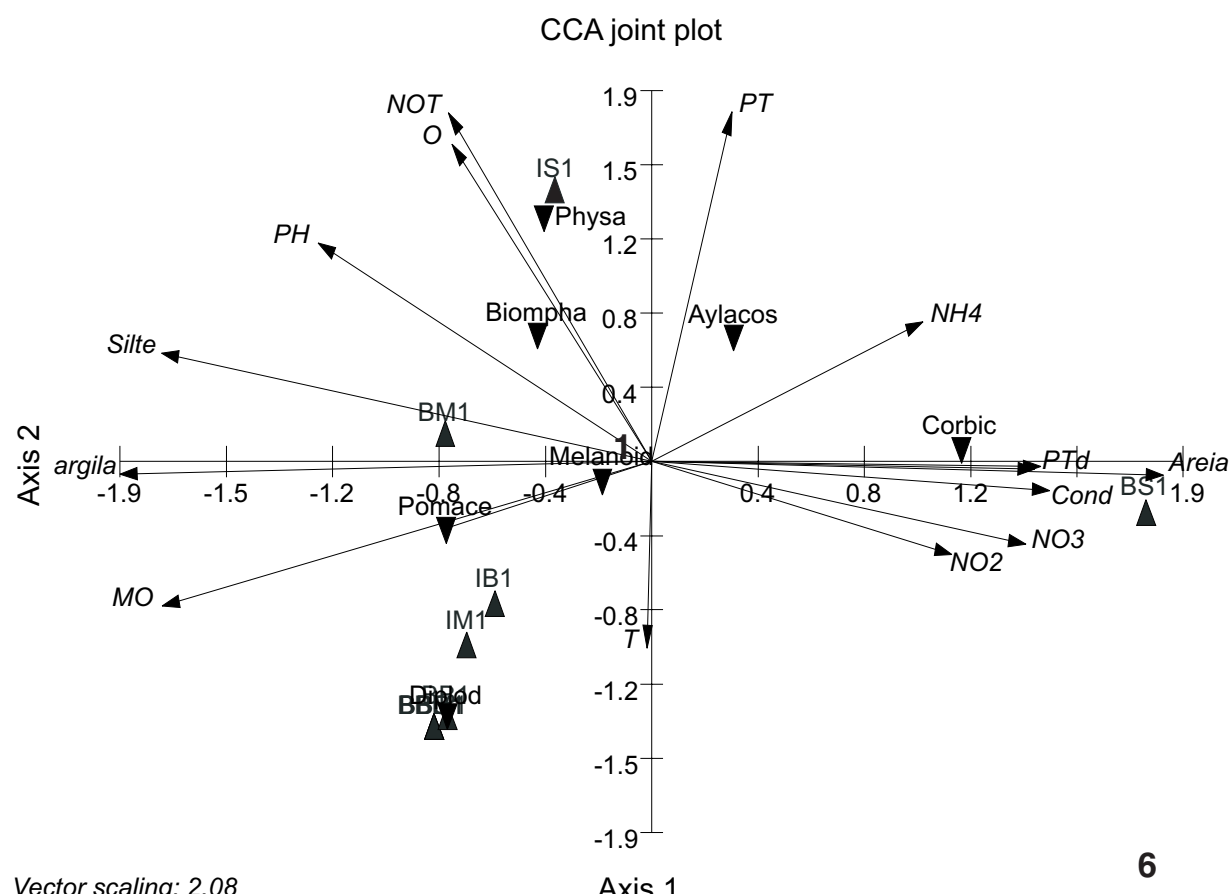

Vector scaling: 2,08

Axis 1

CCA joint plot

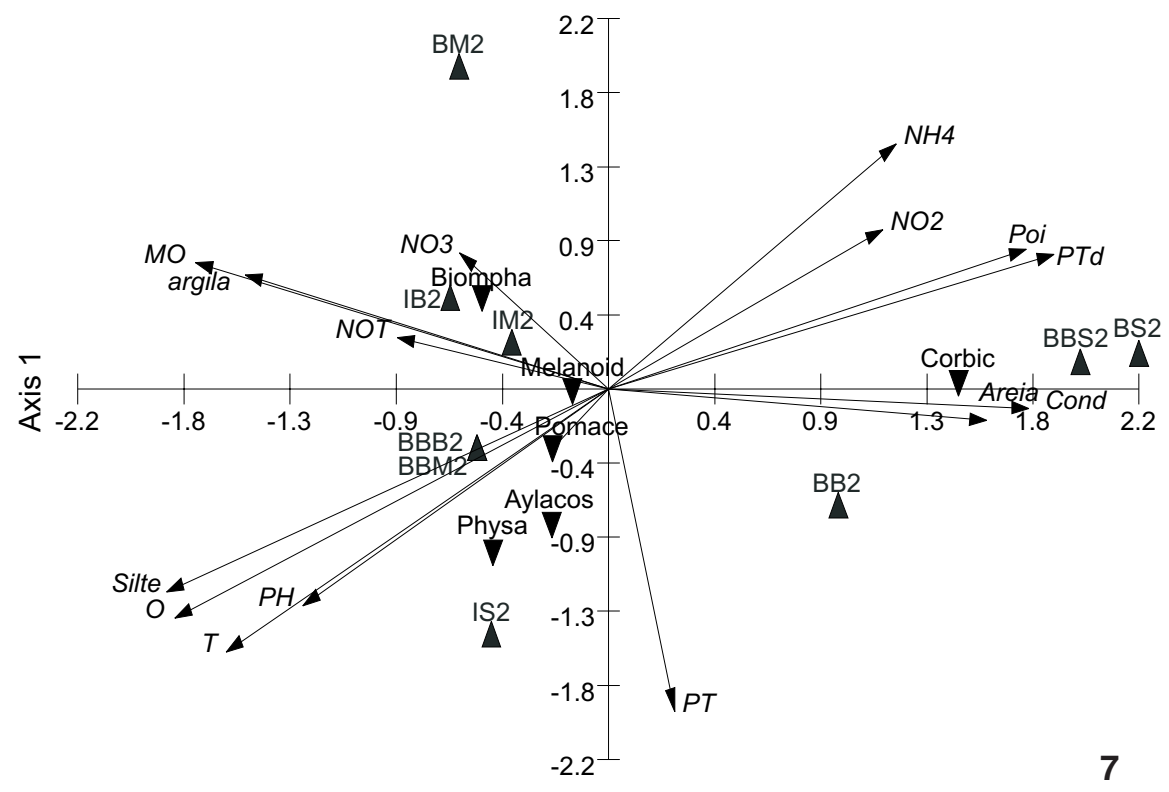

Vector scaling: 2,58

Axis 1

Figuras 6-7. Eixos de ordenação produzidos pela análise de correspondência canônica dos parâmetros das varáveis físicas, químicas e biológicas amostradas nas porções superior, mediana e próxima à barragem das represas de Barra Bonita, Bariri e lbitinga em novembro de 2002 (6) e em agosto de 2003 (7). (B) Bariri, (BB) Barra Bonita, (I) Ibitinga, (S) superior, (M) mediana, (B) barragem, (Physa) Physa cubensis, (Diplod) Diplodon expansus, (Biompha) Biomphalaria spp., (Aylacos) Aylacostoma tenuilabris, (Corbic) Corbicula fluminea, (Melanoid) Melanoides tuberculata, (Pomace) Pomacea canaliculata, (1) período chuvoso, $\left(\mathrm{NH}_{4}\right)$ amônio, $\left(\mathrm{NO}_{2}\right)$ nitrito, $\left(\mathrm{NO}_{3}\right)$ nitrato, (NOT) nitrogênio orgânico total, (PT) fósforo total, (Cond) condutividade elétrica, (T) temperatura. As variáveis ambientais estão escritas em itálico. Os moluscos bentônicos e seus locais de coleta estão representados pelos símbolos $\boldsymbol{\nabla}$ e $\boldsymbol{\Delta}$, respectivamente. 
Apesar dos resultados obtidos no presente estudo indicarem um possível efeito adverso das espécies exóticas sobre as nativas, estes são preliminares e uma avaliação acurada da fauna malacológica requereria um estudo mais detal hado, incluindo a amostragem de diferentes substratos e a utilização de técnicas de coleta adequadas, tendo em vista que já foi demonstrado que algumas espécies de moluscos podem explorar uma variedade de substratos e responder a flutuações sazonais. (FreITAS 1976).

Considerando-se a relevância das represas do médio rio Tietê no contexto econômico e ecológico, estudos mais amplos e de longa duração, envolven do os moluscos e outros componentes da comunidade bentônica serão importantes para a conservação tanto da estrutura biótica como dos serviços ecológicos destes ecossistemas.

\section{CONCLUSÕES}

A ocupação generalizada de M. tuberculata e C. fluminea em todas as represas estudadas e as elevadas densidades destas espécies na represa de Ibitinga, tanto no período seco quanto no chuvoso revelaram o alto potencial invasor destas espécies exóticas.

O efeito de sazonalidade sobre a malacofauna foi evidenciado, sendo a densidade dos moluscos mais elevada no período seco.

A reduzida abundância e densidade das espécies nativas, além da não ocorrência das mesmas na represa de Barra Bonita, sugerem que estes moluscos podem estar em processo de extinção no sistema do médio Tietê.

\section{AGRADECIMENTOS}

À CAPES pela concessão de bolsa de estudo, ao Ministé rio do Meio Ambiente (MMA/BIRD/GEF) e ao CNPq pelo financiamento da pesquisa. A José V. de Lucca, Fernanda T. Marciano, Wagner E.P. Avelar e Luiz R.L. de Simone pelo auxílio em algumas etapas da pesquisa.

\section{REFERÊNCIAS BIBLIOGRÁFICAS}

Armengol, J.; J.G. Garcia; M. Comerma; M. Romero; J. Dolz; M. Roura; B.H. Han; A. VIDAL \& K. Simek. 1999. Longitudinal processes in canyon type reservoir: the case of Sau (ne. Spain), p. 313-345. In: J.G. TundisI \& M. Straskraba (Eds). Theoretical reservoir ecology and its applications. São Carlos, Brazilian Academy of Sciences and Backhuys Publishers, 585p.

Avelar, W.E.P. 1999. Moluscos Bivalves, p.65-68. In: D. Ismael; W.C. Valenti; T. Matsumura-Tundisi \& O. Rocha (Eds). Biodiversidade do Estado de São Paulo. Invertebrados de água doce. São Paulo, FAPESP, vol. 4, 176p.

Barbosa, F.A.R.; J. Padisák; E.L.G. Espíndola.; G. Borics \& O. RoCHA. 1999. The Cascading Reservoir Continuum Concept (CRCC) and its application to the River TietêBasin, São Paulo State, Brazil, p. 425-437. In: J.G. Tundisı \& M. StraskrabA (Eds). Theoretical reservoir ecology and its applications. São
Carlos, International Institute of Ecology, Brazilian Academy of Sciences, Backhuys Publishers, 592p.

CESP. 1998. A conservação e manejo nos reservatórios: limnologia, ictiologia e pesca. São Paulo, Companhia Energética de São Paulo, 163p.

CETESB. 2001. Relatório da qualidade das águas interiores do Estado de São Paulo. São Paulo, Secretaria do Meio Ambiente, Série relatórios, 214p.

Covich, A.P.; M .A. PALmer \& T.A. Crowl. 1999. Therole of benthic invertebrate species in freshwater ecosystems - zoobenthic species influence energy flows and nutrient cycling. BioScience 49: 119-127.

Darrigan, G.A. 1997. Invasores en la Cuenca del Plata. Ciencia Hoy 38: 1-6.

Dudgeon, D. 1989. Ecological strategies of Hong Kong Thiaridae (Gastropoda: Prosobranchia). Malacological Review 22: 3953.

Esteves, F.A. 1988. Fundamentos de Limnologia. Rio de Janeiro, Interciência, FINEP, 545p.

Espíndola, E.L.G.; O. Rocha; A.C. Rietzler; M.B.C. Branco; R. Fracácio; E.M. Moretto; S. Rodgher; W.S. Simith; K.S. Tavares; A.M. Guntzel \& R.H.G. Pereira. 2003. Efeitos da fragmentação em ecossistemas aquáticos: organismos aquáticos, p. 201238. In: D.M. Rambaldi \& D.A.S. Oliveira (Eds). Fragmentação de ecossistemas: causas, efeitos sobrea biodiversidade e recomendações de políticas públicas. Brasília, Ministério do Meio Ambiente, Secretaria de Biodiversidade e Florestas, 510p.

Fernandez, M.A.; S.C. Thiengo \& M.F. Boaventura. 2001. Gastrópodes Límnicos do Campus de Manguinhos, Fundação Oswaldo Cruz, Rio de Janeiro, RJ. Revista da Sociedade Brasileira de Medicina Tropical 34: 279-282.

Fernandez, M.A.; S.C. Thiengo \& L.R. Simone. 2003. Distribution of the introduced freshwater snail Melanoides tuberculatus (Gastropoda: Thiaridae) in Brazil. The Nautilus 117 (3): 78-82.

Fracácio, R.; N. Fenerich-Verani; E.L.G. Espíndola, E.L.G.; O. RoCha; O. Rigolin-Sá \& C.A. Andrade. 2003. Alterations on growth and gill morphology of Danio rerio (Pisces, Ciprinidae) exposed to the toxic sediments. Brazilian Archives of Biology and Technology 46 (4): 685-695.

FreitAS, J.R. 1976. Ecologia de vetores de doenças. O habitat primitivo da Biomphalaria glabrata. Ciência e Cultura 28 (2): 212-217.

Freitas, J.R.; L.C. Bedê; P. de Marco Júnior; L.A. Rocha \& M.B. SAntos. 1987. Population dynamics of aquatic snails in Pampulha Reservoir. Memórias do Instituto Oswaldo Cruz 4: 299-305.

Golterman, H.L.; R.S. Clymo \& M.A.M. Ohstand. 1978. Methods for physical and chemical analysis of freshwaters. Oxford, Blackwell Scientific Publications, 213p.

Hakenkamp, C.C. \& A.P. Margaret. 1999. Introduced bivalves in freshwater ecosystems: the impact of Corbicula on organic matter dynamics in a sandy stream. Oecologia 119: 445-451. 
HenRY, R. \& C.A. Simão. 1984. Evaluation of density and biomass of a bivalve population (Diplodon delodontus expansus) (Kuster, 1856) in a small tropical reservoir. Revue D'Hydrobiologie Tropicale 17:309-318.

ITUARTE, C.F. 1981. Primera noticia acerca de al introducción de Pelecípodos asiáticos em el área rioplatense (Mollusca Corbiculidae). Neotrópica 27:79-82.

JaCoBson, M.K. 1975. The freshwater prosobranchia Tarebia granifera in Oriente, Cuba. Nautilus 89: 106.

KAJAK, Z. 1988. Considerations on benthos abundance in freshwaters, its factors and mechanisms. Internationale Revue der Gesamten Hydrobiologie 73: 5-19.

M ARCKERETH, F.J.H.; J. HeRON \& J.F. TAILING. 1978. Water analysis: some revised methods for limnologists. Kendal, Titus Wilson \& Son, Freshwater Biology Association Scientific Publication, 117p.

Margalef, R. 1983. Limnologia. Barcelona, Omega, 1010p.

MCMAHON, R.F. 1983. Ecology of an invasive pest bivalve, Corbicula, p. 505-561. In: K.M. WILBUR (Ed.). The Mollusca: Ecology. Nova York, Academic Press, vol. 6, 715p.

M мA. 2003. Anexo aos padrões de certificação florestal - Listas de espécies ameaçadas de extinção da fauna e flora brasileiras. Lista nacional das espécies da fauna brasileira ameaçadas de extinção. Disponível na World Wide Web em http://www.imaflora.org/arquivos/ListasNacionaisdasEspeciesAmeacadasdaFaunaeFloraBrasileira.pdf. [Acessado em 17.VIII.2004]

PAmplin, P.A.Z. \& O. Rocha. 2005. Distribuição batimétrica e sazonal de moluscos na represa de Bariri, com ênfase nas espécies exóticas, Melanoides tuberculata (Gastropoda: Thiaridae) e Corbicula fluminea (Bivalvia: Corbiculidae), p. 281-305. In: O. Rocha; E.L.G. Espíndola; N. Fenerich-Verani; J.R. Verani \& A.C. Rietzler (Eds). Espécies invasoras em águas doces. Estudos de caso e propostas de manejo. São Carlos, Editora Universidade Federal de São Carlos, 416p.

PAYNE, A.I. 1986. The ecology of tropical lakes and rivers. Chichester, John Wiley, 301p.

Pointier, J.P. \& B. Delay. 1995. Spread of introduced freshwater snail Melanoides tuberculata (Muller, 1774) on the island of Guadel oupe, French West Indies (Prosobranchia, Thiaridae). Haliotis 24: 109-116.

Pointier, J.P. \& J. Jourdane. 2000. Biological control of the snail hosts of schistosomiasis in area of low transmission: The example of the Caribbean area. Acta Tropica 77: 53-60.

Pointier, J.P.; J.L. Toffart \& M. Lefevre. 1991. Lifetables of freshwater snails of genus Biomphalaria (B. glabrata, B. alexandrina, B. straminea) and one of its competitors Melanoides tuberculata under laboratory conditions. Malacologia 33: 43-54.

Pointer, J.P.; A. Theron \& G. Borel. 1993. Ecology of theintroduced snail M elanoides tuberculata (Gastropoda: Thiaridae) in relation to Biomphalaria glabrata in the marshy forest zone of Guadaloupe, French West Indies. Jornal of Molluscan Studies 59: 421-248.

Revista Brasileira de Zoologia 24 (1): 21-32, março 2007
Rocha, O.; K.S. Tavares; M.C. Branco; P.A.Z. Pamplin; E.L.G. Espíndola \& M. Marchese. 2006. Padrões de biodiversidade em reservatórios e relações com o processo de eutrofização, p. 353-372. In: J.G. Tundisl; T. MatsumuRa-Tundisi \& C. GalliSIDAGIS (Eds). Eutrofização na América do Sul: causas, conseqüências e tecnologias para o gerenciamento e controle. São Carlos, Rede Sul Americana de Eutrofização, 531p.

Simberloff, D. \& P. Stiling. 1996. Risks of species introduced for biological control. Biological Conservation 78: 185-192.

SIMONE, L.R.L. 1999. Moluscos Gastrópodos, p. 69-72. In: D. ISMAEL; W.C. Valenti; T. Matsumura-Tundisi \& O. Rocha (Eds). Biodiversidade do Estado de São Paulo, Brasil: síntese do conhecimento ao final do século XX. São Paulo, FAPESP, 176p.

StRASKRABA, M. \& J.G. TUNDISI. 1999. Reservoir water quality management. Shiga, ILEC, 229p.

StRAYER, D.L. 1999. Effects of alien species on fresh water mollusks in North America. Journal of the North American Benthological Society 18 (1): 74-88.

Suguio, K. 1973. Introdução à sedimentologia. São Paulo, Editora E. Blücher, 317p.

Thompson, F.G. 2004. An identification manual for the freshwater snails of Florida. Available in the World Wide Web at: http://www.flmnh.ufl.edu/natsci/malacology/flsnail/snails1.htm [Accessed in 17/VIII/2004]

TundISI, J.G. 1988. Limnologia e manejo de represas. ACIESP 1: 1-76.

TundISI, J.G. 1990. Limnology and eutrophication of Barra Bonita reservoir, S. Paulo State, Southern Brazil. Archiv für Hydrobiologie Beihefte Ergebnisse der Limnologie 33: 661-676.

Tundisl, J.G.; O. Rocha; T. Matsumura-Tundisl \& B. Braga. 1998. Reservoir Management in South America. Water Resources Development 14: 141-155.

Vaz, J.F.; H.M.S. Teles; M.A. Correa \& S.P.S. Leite. 1986. Ocorrência no Brasil de Thiara (Melanoides) tuberculata (O.F. Muller, 1774) (Gastropoda, Prosobranchia), primeiro hospedeiro intermediário de Clonorchis sinensis (Cobbold, 1875) (Trematoda, Plathyhelmintes). Revista Saúde Pública 20 (4): 318-33.

Veitenheimer-Mendes, I. 1981. Corbicula manilensis (Philippi, 1844) molusco asiático, na bacia do rio Jacuí e do Guaíba, Rio Grande do Sul, Brasil (Bivalvia: Corbiculidae). Iheringia 60: 6374.

VITOUSEK, P.M. 1990. Biological invasions and ecosystem processes: towards integration of population biology and ecosystem studies. Oikos 57: 7-13.

WELCH, P.S. 1948. Limnological methods. Philadelphia, Blakiston, 381p.

WiLLIANSON, M. \& A. FitTER. 1996. The varying success of invaders. Ecology 77: 1661-1666.

Recebido em 08.III.2006; aceito em 28.II.2007. 